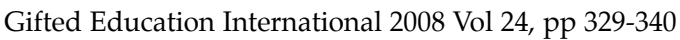

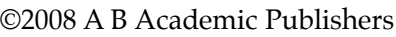 \\ News around the world
}

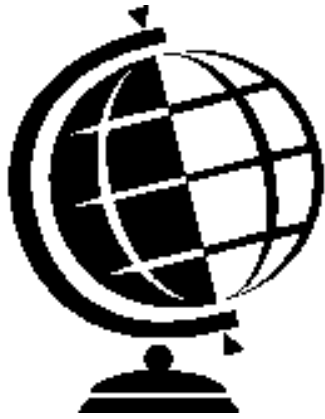

\author{
J.G. Maree \& G. Prins
}

Faculty of Education, University of Pretoria, 0001 Pretoria

\section{the experiential application of TASC in a post-graduate environment}

Introduction: The need for the study

All students have to pass (inter alia) a compulsory course in Research Methodology (NME 725, Introduction to Quantitative Research) in order to obtain an honours degree from the University of Pretoria's Faculty of Education,. Students are not just expected to master the content of the course module. Instead, after having completed the module successfully, they are expected to apply their newly acquired knowledge and skills practically in new situations. Having successfully completed the module, they should be able to do basic quantitative research in education, report on their research in a professional way and succeed in getting the results published. The knowledge acquired in this module should help them to solve problems in their daily lives and enable them to find solutions to questions they have been asking about learners' performance or the need for improving teaching methods.

The stated outcomes of the module are to help students (inter alia) to:

- carry out independent research;

- explore the potential significance and use of statistics as an aid in the research process;

- master basic, generic and critical skills of statistical analysis in the research process;

- experience the potential significance (as well as limitations in the use) of statistics as an aid in dealing with challenges and problems;

- master basic skills of networking and 
team work in practice;

- carry out research in a multicultural team context;

- experience the value of statistics in carrying out cross-cultural research;

- start disseminating this research by way of writing articles in a team context; and

- facilitate the interpretation of basic statistical procedures (as part of research at post-graduate level), as indicated per unit.

Yet, for a number of reasons, many students find the course extremely challenging and the annual pass rate is low (usually about $57 \%$ of the students pass). During marking, the following general mistakes regularly appear.

- Students do not interpret the questions correctly.

- Instructions are not understood.

- Examinations typically conclude with a reading passage (an extract from a longer article that recently appeared in a scholarly journal) upon which a number of questions are based. Students have to answer a number of questions, based on their reading of this passage. However, the vast majority of students provide little evidence of being able to apply their newly acquired knowledge in real-life contexts.

In attempting to find solutions to these challenges, we have tried out various approaches during our two-weekly practicals over the past few years, with varying degrees of success.

\section{Purpose of the current study}

Viewed against the background of the stated outcomes of the course, it became clear that many students fail to benefit optimally from the course, despite our best efforts to facilitate state-of-the-art teaching and tutorial classes. *Email:
We became aware that a significant percentage of the students appeared disillusioned with the practicals. Given the possible influence of their experience in the practicals on the way that they will think about and approach their own research, the necessity to adapt the practicals to a more acceptable format to suit the needs of our particular students became clear. Guzman (2000) maintains that while numbers can uncover a trend, the use of qualitative observations may help to explain why certain trends exist and strategies are suggested to circumvent or change these trends. Acting upon the truth of this statement, it was decided to undertake a qualitative action research study which would explore the students' experiences, focusing on their attitudes. After having attended an exciting and motivating TASC training session presented by Belle Wallace (2007b) at the University of the North-West (Potchefstroom Campus), and discussing the issue with Belle, we decided to apply what we had learnt during this workshop at the University of Pretoria. We further based our decision to use the TASC Problem-solving Model during our practicals when dealing with the students, as these practicals allow for more flexible teaching in the case of smaller groups.

\section{The major tenets of TASC in the university context}

We based our intervention on the Thinking Actively in a Social Context (TASC) Framework (Wallace \& Bentley, 2001; Wallace \& Maker, (in press)) so eloquently explained by Wallace (2007b) in August 2007. In a nutshell the TASC Framework entails the following principles:

Thinking. Thinking is seen as a dynamic process and intelligence is not viewed as a fixed, unchanging capacity (Wallace, 2007a). Consequently the content to be taught needs to be understood and different ways of explaining and 
understanding have to be taken into account.

Actively. Only by being actively involved in the learning process can students truly claim to have learnt thoroughly (take ownership of their learning).

Social. We do not only learn from others, but we also learn through explaining concepts to others. In a social setting such as a university, students are not always willing to interact. By grouping them they not only have to interact with others, but also are enabled to learn from people who would otherwise have merely remained familiar faces to them.

Context. In any classroom there are representatives from many different social and cultural realities. Through interaction students learn more about other settings and also come to appreciate the similarities and differences that are presented to them.

\section{Aims of the study}

The primary aim of this study was to conduct a pilot investigation aimed at enhancing the understanding of the basic principles contained in a compulsory course in Research Methodology (NME 725, Introduction to Quantitative Research) by a sample of honours degree students at the University of Pretoria's Faculty of Education. Secondary aims included preliminary investigating guidelines for adapting our Research Methodology practical course to a format more suited to the needs of our students.

\section{Research question}

In our attempt to enhance the understanding of the basic principles contained in a compulsory research module (Research
Methodology 725), the following question was considered:

- What are the reported and observed experiences of the 2007 final year students in Research Methodology when applying the TASC approach in their practicals?

\section{Research design}

\section{Subjects and sampling techniques}

\section{Sample}

Purposive, convenience sampling was applied, in the sense that the entire Research Methodology 725 class of 2007 at the University of Pretoria (Faculty of Education) was elected to take part in the research (155 students divided into two classes).

Participants attended five 90-minute fortnightly sessions between August and November 2007.

\section{Action research}

Mouton (1996:175) asserts that the objective of a research design is to plan, structure and execute the relevant project in such a way that the validity of the findings is maximised. The approach adopted in this project was action research, described by Cohen, Manion and Morrison (2000). In essence, this is a procedure which is aimed at dealing with a concrete problem in an immediate situation. A qualitative approach is used in this article as a methodological framework for generating and analysing data. Our aim was to facilitate a deep understanding of the reason why students find the course so challenging from an insider perspective, and to describe and understand rather than explain and predict their behaviour (Babbie, Mouton, Payze, Vorster, Boshoff \& Prozesky, 2001). The key to this approach is gaining an 
understanding of individual perspectives and experiences and understanding the phenomenon in its natural setting (Fraenkel \& Wallen, 2006; Maykut, \& Morehouse, 1994).

In the production of new knowledge, universities generally operated within a Mode 1 epistemology of learning, id est, learning that is factual, systematic, explicit, objective, codified, fragmenting into more specialisations, reductionist, orderly, empirical, establishment-minded, contextindependent, theory-bound, authoritarian, impersonal, universal and transcultural. More recently though, universities have moved to Mode 2 epistemological approaches in which learning is conceived and assumed to be holistic, context-driven, mission-oriented, multi-authored, heterogeneous, divergent, reflexive, personalised, insecure, entrepreneurial and workable (Hills \& Tedford, 2003).

The process followed during the current project can be represented as follows.

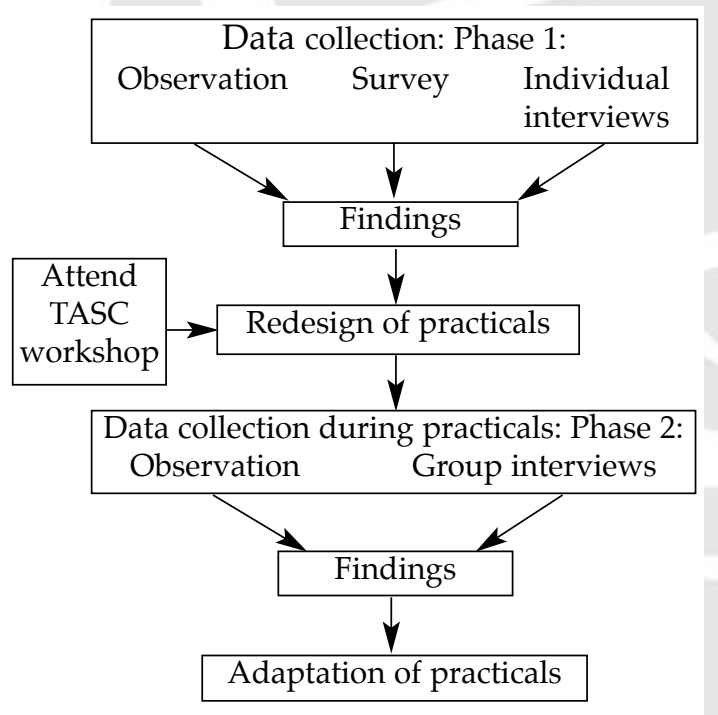

Figure 1: Research strategy

\section{The key stages of the TASC Problem- solving Model}

\section{Gather and Organise}

The students were encouraged to first explore each new task/situation before simply 'diving in' to find a solution. We especially focused on the following four questions:

- How much do I understand about the task?

- What information do I already have?

- Have I encountered anything like this before?

- What questions can I ask to help me understand what is required?

The students worked in groups to answer these questions. It was interesting to see that they quickly started to ask each other these questions. They spontaneously changed the 'I' questions to 'we' questions and started to organise the available information. During the initial stage they also learned how to use different mindmaps to enable them to come to terms with new concepts by linking them on existing knowledge

\section{Identify}

During this stage students were encouraged to break the tasks down into manageable parts and not only identify what they could do, but also what they could not. This gave them the opportunity to identify different persons in the group who could carry out the different tasks instead of merely following a 'group leader' system. They were strongly encouraged to make use of visual aids such as diagrams in order to clearly identify what they were doing.

\section{Generate}

Wallace (2007b) emphasised the fact that the most important thing to remember at this stage was that there was no right or wrong answers, only a flow of ideas. The students 
were asked to brainstorm and not to get stuck on one initial idea. This ensured that everybody could contribute to the process. This also generated the feeling that the persons in a specific group could be seen as a valuable resource.

\section{Decide}

The most important decision to make is which of all the ideas that were generated, were the best to use? After deciding on a course of action, the group has to decide on the different steps that need to be taken in order to carry out the task at hand. This has to be done in such a way that it can be recorded so that each of the group's members can understand and not just recall when they have to revise their notes for the examination.

\section{Implement}

The most difficult skill to convey during the implementation stage is flexibility. During the first few sessions the students were so set on 'deciding on a plan of action' that they didn't want to change anything even when they clearly saw that their initial idea was not working. The more they worked through the stages the easier it became to amend their original plan.

\section{Evaluate}

The students tended to assess themselves and each other by merely checking their answer to the one provided on the memorandum or in the text book. After working through the stages a few times they realised that it was not only the answer that was important, but also the process. Deciding what thinking skills and strategies one has used and whether these were always the most appropriate ones enables a person to use similar skills when solving other (similar and not so similar!) problems.

\section{Communicate}

The students needed to be shown how to communicate their ideas to demonstrate that they have gained knowledge and understanding through completing the different stages. We applied the following principle: 'If you think it, say it' (Stephenson, 2001:9). What made this stage unique was that the students, who speak languages that differ from the language of instruction (English), tended to communicate their answers and experiences of the task in their own mother tongue; id est, they explained different concepts to each other in the language in which they felt most comfortable.

\section{Learn from experience}

During this stage the students had very heated discussions on what they wanted to change and what not to change: what they wanted to do in a different way and what not to do. It was decided that the new strategies would work better if they first were given a few minutes to write down their own reflections on matters such as the following:

- What would I change if I was faced with the same problem?

- What would I keep the same?

- What did I contribute to the group decision?

- How was my thinking changed by the group?

- How else can I use what I have learned?

\section{Data collection and analysis: Phase 1}

The students were observed during various practical sessions prior to our intervention. Students were provided with a survey sheet to gain information on their attitudes towards the module and the course content. The survey included questions on the extent 
to which they found the practicals enjoyable, creative and useful for the development of their own skills and understanding regarding research, as well as for application in their future research. Subsequently, semistructured, individual, in-depth interviews were carried out with a focus group to determine their attitudes to the practicals. The interviews also created an opportunity to learn more about their daily lives in order to help them identify appropriate examples to use in class.

The data were then analysed to identify factors influencing the attitudes of the students on the practicals. Themes which emerged from Phase 1 were subsequently used to determine criteria for success in designing an intervention programme. These criteria were prioritised.

\section{Data collection and analysis: Phase 2}

Themes which emerged from the Phase 1 data analysis served as a basis for the adaptation of the practicals, along the lines suggested by Wallace (2007b).

We structured our intervention along the following lines (Wallace, 2007b).

a. First, we gave a brief introduction with regard to the TASC theoretical underpinnings.

b. Next, we did an enjoyable practical exercise reflecting on what the brain was doing at each stage of the exercise. This 'fun' introduction was necessary to allow students 'thinking and reflecting space' that is relatively free from content.

c. We then asked the students to 'create something to communicate to other students the most important values for them as prospective practitioners'.

d. In the next stage we recorded students' reflective comments in the 'Learn from Experience stage' in two phases, namely a. partly as a whole class and b. partly in small groups of four students. This part of the exercise constituted initial research within the paradigm of Living Theory (Whitehead \& McNiff, 2006).

e. This was followed by further implementation. We provided students with practical problems and asked them to use the TASC Framework to resolve the issues involved in each case. In the reflective stage we invited them to record their thoughts and reflections on the TASC process.

Due to time constraints, we decided not to administer a pre- and posttest. We argued that we would need a longer time span to allow for 'significant' student change.

To assess students' attitudes towards the module after completion of the intervention, students were invited to present themselves for in-depth interviews with lecturers. Observation of these students engaged in the practicals was followed up by semistructured, in-depth group interviews. Conversations were recorded and data were analysed on the basis of Morse and Field's approach (comprehending, synthesising, theorising and recontextualising) (Morse, 1994; Morse \& Field, 1996).

We applied the TASC structure categories (Wallace, 2007a) as our predetermined categories to analyse students' comments (McMillan \& Schumacher, 2001).

Table 1 records the criteria considered in the validation process and how they were applied in both data collection and data analysis. 
Table 1: Criteria implemented in the validation process

\begin{tabular}{|l|l|}
\hline Data collection & Description \\
\hline Strategy & $\begin{array}{l}\text { Obtained literal statements from participants e.g. verbatim } \\
\text { accounts of conversations and interviews, as well as } \\
\text { quotations from documents. }\end{array}$ \\
\hline $\begin{array}{l}\text { Participant language: } \\
\text { verbatim accounts }\end{array}$ & $\begin{array}{l}\text { Recorded concrete, precise and detailed descriptions of the } \\
\text { participants and the situations in fieldnotes. }\end{array}$ \\
\hline Low-inference descriptors & $\begin{array}{l}\text { Rephrased and probed to obtain more complete and nuanced } \\
\text { meanings during interviews. }\end{array}$ \\
\hline Member checks & $\begin{array}{l}\text { Participants reviewed the researchers' synthesis of all } \\
\text { interviews. }\end{array}$ \\
\hline Participant review & \multicolumn{2}{|l|}{ (Adapted from McMillan \& Schumacher, 2001) } \\
\hline Data analysis & $\begin{array}{l}\text { The participants were asked to validate the data analysis } \\
\text { process. The participants were also asked whether they could } \\
\text { confirm the results of the data analysis throughout the } \\
\text { process. }\end{array}$ \\
\hline Participant validation & $\begin{array}{l}\text { The researchers acted as objectively as possible while } \\
\text { analysing the research data. }\end{array}$ \\
\hline $\begin{array}{l}\text { Avoiding subjective } \\
\text { interpretation }\end{array}$ & $\begin{array}{l}\text { The research data were carefully coded by the researchers and } \\
\text { verified by an external coder. }\end{array}$ \\
\hline $\begin{array}{l}\text { Avoiding poor coding } \\
\text { of qualitative data }\end{array}$ & $\begin{array}{l}\text { Generalisations were not made beyond the capability of the } \\
\text { data to support such statements. The external coder assisted } \\
\text { in this process. }\end{array}$ \\
\hline $\begin{array}{l}\text { Avoiding making } \\
\text { unsupported inferences }\end{array}$ & $\begin{array}{l}\text { Data were not used selectively to falsely verify findings. An } \\
\text { external coder assisted in this process. }\end{array}$ \\
\hline Avoiding selective use of dations & $\begin{array}{l}\text { The researchers guarded against their own expectations, } \\
\text { misperceptions and need to find answers that would support } \\
\text { their preconceived notions concerning the research. The } \\
\text { external coder assisted in this process. }\end{array}$ \\
\hline Avoiding researcher bias & Adapted from Cohen, Manion \begin{tabular}{l} 
Morrison, 2000) \\
\hline
\end{tabular} \\
\hline
\end{tabular}

\section{Ensuring trustworthiness}

Trustworthiness (Guba in Schurink, Schurink, \& Poggenpoel, 1998) of the results was facilitated in the following way. Much time was spent with participants during the course of lectures and practicals, which facilitated rapport and helped students feel at ease. Qualitative researchers with many years' experience in interviewing conducted the interviews in an attempt to eliminate bias. The lecturers were both highly trained and vastly experienced, not only in teaching research methodology at tertiary level, but also in the implementation of anti-bias programmes. Trustworthiness was further 
enhanced by peer examination (researchers reviewed each other's work at all stages), independent coding and comparison of information at different stages of the research. The relationship of trust between the lecturers and the students and the fact that students were motivated to contribute to the adaptation of the practicals to their needs further facilitated trustworthiness.

\section{Limitations of the study}

This was a limited, local, naturalistic study with limited inferential value. Time constraints on the part of the researchers and timetable restrictions on the part of the students could be considered as limitations on the study. Furthermore other researchers might interpret the findings differently.

\section{Ethical aspects}

Permission was requested and obtained in writing from the university and the students in order to conduct the research and publish the findings. Assurance was given that no individual would be identified.

\section{Determining the attitudes of the students to the practicals: Phase 1}

Semistructured (individual and group), indepth interviews yielded interesting data. Findings indicated that the students were positive about the practicals, but experienced a number of significant frustrations which centred in two main themes which emerged from the data analysis, viz. the need for more background information, real-world context, and overemphasis on passing the end-of-theyear examination.

These themes will subsequently be discussed, while supporting findings from the other two instruments (observation of students during practicals and a survey sheet) will be mentioned where applicable.

\section{Need for background knowledge}

Students regularly vented their frustrations about facets of the module in verbal and non-verbal ways. During interviews one of the common attitudes towards the practicals that emerged, was one of feeling 'lost'. Some comments were:

'If only I had followed mathematics at school.'

'I do not have any background knowledge.'

'I find it extremely difficult to follow what is being said in class and practicals, because I do not understand where you come from.'

Our observations indicated that the students expected considerably more individual assistance to deal with the demands of the course. This 'ability versus demand gap' could be addressed by scaffolding, a process of guiding the learner from what is presently known to what needs to be known (Maree, Scholtz, Botha, \& van Putten, 2005). Scaffolding allows students to perform tasks that would normally be slightly beyond their ability without the assistance and guidance of the lecturer.

\section{Real-world context}

Many students expressed the view that they found it extremely difficult to apply the knowledge obtained in real-life contexts.

'Where will I ever use this knowledge?'

'How can I apply what I don't understand in real-life contexts?'

'I learn most of the work in parrot-like fashion just to make sure that I pass. However, I cannot see the link between what I study and practical research.' 


\section{Overemphasis on passing the end-of-the- year examination}

The vast majority of students were more interested in passing the course than in obtaining knowledge that could be applied in research settings, borne out by the following quotations:

'Everything will be okay if only I can pass the course.'

'I cannot see the purpose of the course and I am only interested in obtaining 50\% at the end of the year.'

'The course is too full. You cannot expect us to understand and apply statistics in six months; all that matters right now, is to get a pass mark in the examination.

\section{Changes in the attitudes of students after the adaptation of the practices along the TASC framework (Phase 2)}

\section{Thinking}

Students provided evidence of beginning to think critically about module contents; to argue and reason at higher-order levels of thinking, borne out by the following quotes.

'It's amazing to see that research has always been a part of my life, from working out the mean on a report card to the phone calls I get for insurance.'

'I gladly admit that I was wrong in assuming that I would never master the course: after a few sessions, insight seemed to 'grow' on me.' 'I will always look at toffees and think of sampling.'

'It was nice to see how my creative mind found interesting ways to solve the very logical problems asked.'

'The most important moment to me was when I eventually realised that I could use what I had learned to improve my own teaching.'

\section{Actively}

Overall there was an increased willingness by students to take an active part in their own learning; a new sense of empowerment.

'Talking to others in my group, listening and explaining to them in return made me realize that I may not know everything, but as a group we are pretty close to it!'

'Most of the new terms were Greek to me, but after seeing them on coloured paper in my group's mind map, it all made sense.'

'It was comforting to learn that others experienced the same problems as I did; even more, it was enlightening to hear my peers telling me what the lecturers did, namely: 'Unless you do the sums and read on your own, you cannot expect to make the contents your own.'

\section{Social}

Working together in groups and socialising 'academically' soon began to pay off and students reaped the benefits of their efforts, evidenced by the following quotes.

'I used to feel extremely dejected about this subject. Working and talking with my fellow students and learning about their own despondence (and the way in which they handled these emotions) have made me realise that I am not 'alone'.'

'I am more confident when voicing my opinion in class, knowing that even if it is not $100 \%$ correct it is still valued and part of the learning process of the whole group.'

'It was interesting to see that even if we approach problems differently we still get similar solutions.'

'The support and encouragement of the group made me realise that I had a role to play in helping myself and the rest of the group, too.'

'When I was down, there was always someone else that would cheer me up with a joke or a comforting remark.' 


\section{Context}

In our lecture room there were representatives from many different social and cultural 'worlds'. By interacting with fellow students from vastly different realities than their own, our students learned about these and came to a deep understanding and appreciation of these settings, as well as the similarities and differences that were presented to them. The following quotes exemplify this statement.

'I was amazed to see that even the so-called 'clever' students had to work hard and battled with some concepts as well.'

'It was a privilege to learn from students who teach in schools whose populations differ vastly from my own. We even established a buddy system whereby we will share papers, ideas and research results.'

More than anything: It was indeed interesting to note how students from across the entire continuum of social and cultural backgrounds could find common ground on which to solve mutual tasks.

\section{Concluding remarks}

The results seem to show that the TASC approach could be tailored to enhance learning at tertiary level as well. Even though our initial so-called tutor system was in a way already aligned with this approach to teaching and learning, we focused specifically on improving the following facets of our practicals:

- We allowed for differentiated, personalised learning activities in a group and in social contexts to a much greater extent.

- We did not base all contents that were dealt with during practicals strictly on our pre-set curriculum, but, instead, allowed for extra information as needed during studying and in tailoring problems aimed at optimising acquisition of problem-solving skills.

- We broke complex tasks up into smaller chunks, and encouraged students to make optimal use of visual aids to identify problematic areas.

- We encouraged an 'open' approach, urging students to brainstorm problems without wondering whether what they did were 'right' or 'wrong'.

- We pleaded with students to remain open and flexible, to be willing to alter their initial, original plans of action; to work together to decide which ideas were 'best' to apply.

- We urged students to reflect constantly, to assess their own work and the work of their peers continuously and to communicate their ideas at all stages.

In conclusion: First of all, our results are consistent with those reported on by Wallace (2007b). It is clear that the attitudes of the students were transformed to positive, following the implementation of the intervention programme. Students became more actively involved in the practicals and there was clear evidence that students became more motivated and committed as the practicals progressed. We realise, though, that we will need more time to apply the TASC approach in future, in an attempt to help students 'unlearn the habit of being spoonfed' (Wallace, 2007c) and acquire innovative ways to facilitate independent and active learning. Our current study paved the way for further research to determine whether students' attitudes towards NME 725 can be improved by offering the TASC approach to learning facilitation. We aim to apply the same principles again in 2008, and apply a preand posttest design to assess the results of our intervention quantitatively as well. We are confident, though, that our intervention will not only impact on students' quantitative achievements, but especially, 
and more importantly, on their ability to conduct real-life research. Moreover, we are hopeful that those students $(95 \%$ of whom are teachers) will apply TASC principles in their own classrooms. Since it is common knowledge that teaching interacts with learning styles to discourage or encourage certain types of students, we cannot overemphasize the importance of urging students to think about their own learning innovatively, especially against the backdrop of the history of rote learning at schools in South Africa that has put many students at a serious disadvantage. In our ever-changing world, we believe that the need for innovative approaches in teaching and learning is greater than ever, making it imperative for all lecturers and educators to reconsider their teaching and learning design and delivery approaches to accommodate different learning and thinking style preferences in an attempt to maximise learning.

\section{References}

Babbie, E., Mouton, J., Payze, C., Vorster, J., Boshoff, N., \& Prozesky H. (2001). The practice of social research. Oxford: Oxford University Press.

Cohen, L., Manion, L., \& Morrison, K. (2000). Research methods in education (5th edition). London: Routledge.

Fraenkel, J. R., \& Wallen, N. E. (2006). How to design and evaluate research in education. 6th ed.) Boston: McGraw-Hill.

Guzman, N. (2000). Reflection on undergraduate chemistry laboratory: A qualitative research study. http:/ / web.uccs.edu/bgaddis/leadership/ interview.htm. Retrieved March 12, 2002.

Hills, G., \& Tedford, D. (2003). The education of engineers: the uneasy relationship between engineering, science and technology. Global Journal of Engineering Education, 7(1), 17-28.
Maree, J. G., Scholtz, S., Botha, H. J., \& van Putten, S. (2005). The experiential modification of a computer software package for graphing algebraic functions. South African Journal of Education, 25(2), 61-68.

Maykut, P., \& Morehouse, R. (1994). Beginning qualitative research. London: Falmer Press.

McMillan, J. H., \& Schumacher, S. (2001). Research in education: A conceptual introduction (5th edition). New York: Addison-Wesley Longman Inc.

Morse, J. M. (1994). Emerging from the data: The cognitive processes of analysis in qualitative inquiry. In Morse, J.M. (ed.) Critical issues in qualitative research methods. Thousand Oaks: Sage.

Morse, J. M., \& Field, P. A. (1996). Nursing research: The application of qualitative approaches. London: Chapman \& Hall.

Mouton, J. (1996). Understanding social research. Pretoria: J.L. van Schaik Publishers.

Murphy, E. (1996). A room with a view. http:/ / www.stemnet.nf.ca/ elmurphy/ emurphy/home.html. Retrieved October, 7, 2002.

Schurink, E., Schurink, W., \& Poggenpoel, M. (1998). Focus group interviewing and audiovisual methodology in qualitative research. In De Vos, A. S. (Ed.). Research at grassroots: A primer for the caring professions. Pretoria: J.L. van Schaik.

Stephenson, D. (2001). Creative thinking. Colchester, Essex: Claire Publications.

Steyn TM 1998. Graphical exploration as an aid to mastering fundamental mathematical concepts: An instructional model for mathematical practicals. Master's dissertation. Pretoria: University of Pretoria.

Wallace, B., \& Bentley, R. (2001). Teaching thinking skills across the middle years. London: David Fulton Publishers.

Wallace, B. (2007a). Workshop notes handed out by Belle Wallace. Introductory workshop: Introducing TASC into tertiary environments. University of Pretoria. 15 August 2007. 
Wallace, B. (2007b). Introductory workshop: Introducing TASC into tertiary environments. University of the North-West, Potchefstroom Campus. 16 August 2007.

Wallace, B. (2007c). Personal communication with Belle Wallace, 2007.

Wallace, B., \& Maker, J. (in press).
DISCOVER/TASC: An approach to teaching and learning that is inclusive yet maximises opportunities for differentiation according to pupils' needs. In Shavinia, L. (Ed.) (In press) The Handbook of Giftedness. New London: Springer Science.

Whitehead, J. \& McNiff, J. (2006). Action research: Living theory. Thousand Oaks: Sage.

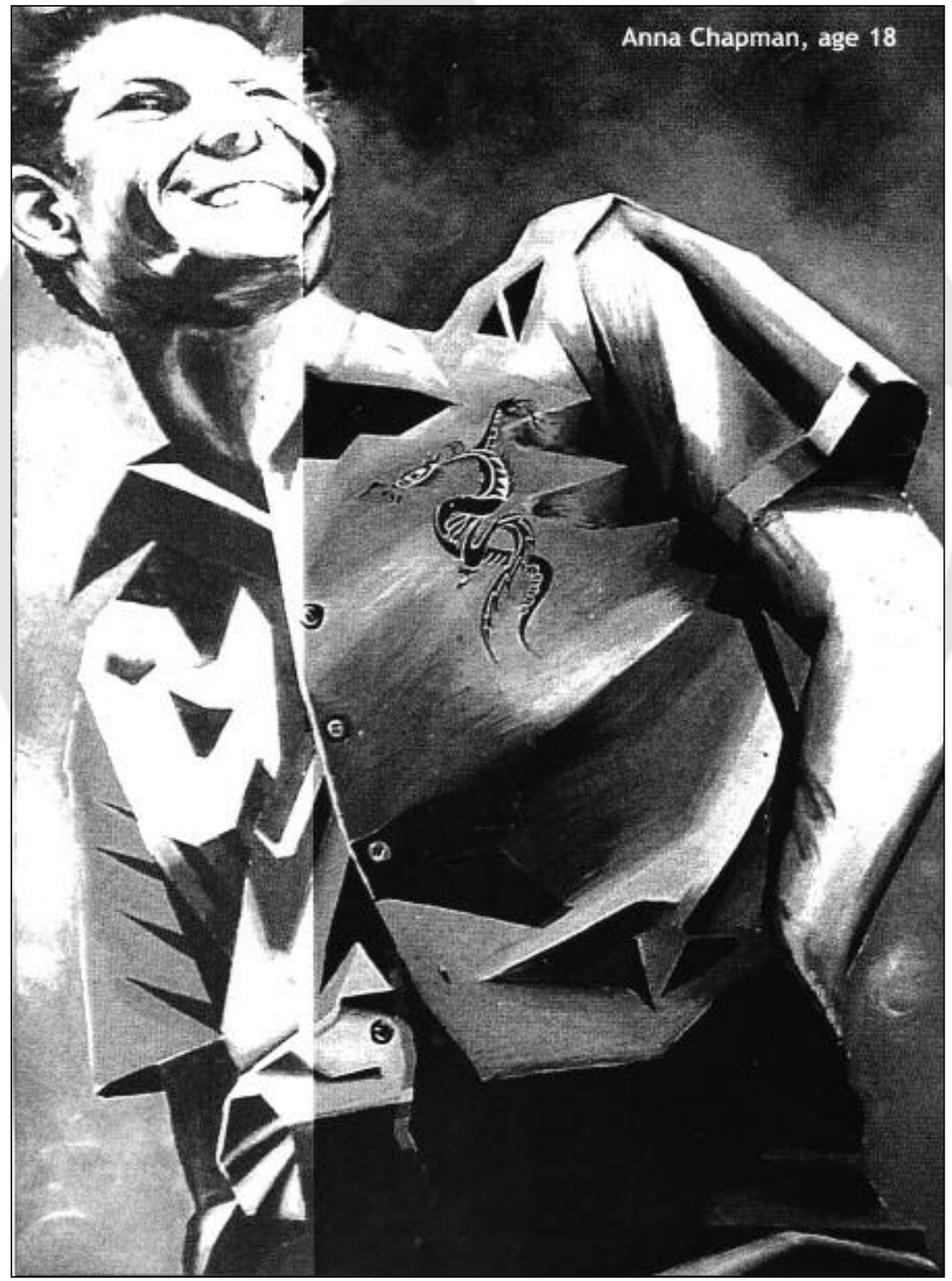

ANNA CHAPMAN, age 18 